\title{
Abrikossoff's rhabdomyoma presenting as a primary breast tumor: a case report
}

\author{
Samar Elkhateb • Mostafa Azzouzi-Idrissi • \\ Michèle Nicaise $\cdot$ François Gielen • \\ Louise Masters-Watkins • Dominique Lipombi
}

Received: 31 July 2007 / Accepted: 2 October 2007 / Published online: 17 November 2007

(C) Springer-Verlag 2007

\begin{abstract}
The granular cell rhabdomyoma, or myoblastoma, is commonly known as Abrikossoff's tumor. It is a rare benign tumor thought to originate from the Schwann cell, and can occur anywhere in the body. When occurring in the breast, the clinical and radiological signs can mimic a primary breast carcinoma. Our case involves a patient who presented via the routine breast screening program. The combination of mammography and sonography suggested a malignant lesion. An ultrasound-guided microbiopsy of the suspicious nodule gave the diagnosis of a rhabdomyoma, and this was confirmed by immunohistochemical studies. The definitive histopathology result confirmed an Abrikossoff tumor, which was completely excised with clear margins of
\end{abstract}

S. Elkhateb $\cdot$ M. Azzouzi-Idrissi

Université sidi Mohamed ben Abdellah,

Fez, Morocco

S. Elkhateb · F. Gielen

Université libre de Bruxelles,

Brussels, Belgium

S. Elkhateb · F. Gielen $\cdot$ L. Masters-Watkins $\cdot$ D. Lipombi

Centre Hospitalier Régional de la Haute Senne,

Soignies, Belgium

M. Nicaise

Université catholique de Louvain,

Brussels, Belgium

M. Nicaise

Institut de Pathologie et de Génétique,

Gosselies, Belgium

S. Elkhateb $(\bowtie)$

Institut Jules Bordet,

Boulevard Waterloo, 121,

Bruxelles 1000, Belgium

e-mail: elkhatebsamar@yahoo.fr healthy breast tissue. The microbiopsy and immunohistochemical studies allowed the diagnosis to be confirmed and avoided any unnecessary surgery.

Keywords Granular cell tumor · Breast rhabdomyoma . Tumorectomy $\cdot$ Immunohistochemical studies .

Schwann's cell

\section{Introduction}

The rhabdomyoma, also called a granular cell tumor, is a soft tissue tumor of as yet uncertain histogenesis [1]. It was first described by Abrikossoff in 1926 as a granular cell rhabdomyoma [2]. It can occur anywhere in the body. Ten to $15 \%$ of reported cases are found in aerodigestive and genital mucosae, and it can also be found in all internal viscera [3]. In $5 \%$ of cases, it affects the mammary gland [3]. It may present as a firm or hard mass, which may be well circumscribed or stellate in nature. As it proliferates it infiltrates between the breast ducts and encircles the glands, which gives it a malignant appearance.

In spite of its infiltrating character, the granular cell tumor within the breast is a benign lesion. It is curable by simple excision [4]. The exact histological diagnosis usually comes as a surprise.

Our team reports a case of an Abrikossoff tumor in the breast, presenting both clinically and radiologically as a breast carcinoma.

\section{Case report}

The subject is a 67-year-old multiparous woman, who has the following risk factors for breast cancer: obesity 
(126 kg), hypertension, and late menopause. Her gynecological history consisted of uterine fibroids.

The patient presented spontaneously to the national breast screening program. On clinical examination a flat medial area of the right breast was noted.

The mammography showed a spiculated hyperdense area $15 \mathrm{~mm}$ in diameter in the medial area of the right breast (Fig. 1), which on ultrasound scan translated as a right medial supraequatorial heterogeneous hyperechogenic area of $16 \mathrm{~mm}$ in diameter. It was classified BIRADS V.

An ultrasound-guided Trucut microbiopsy was carried out. The histology was in favor of a granular cell tumor of Schwann cell origin. This was confirmed by immunohistochemistry.

The treatment involved preoperative localization of the lesion with black carbon-based ink, followed by a tumorectomy under general anesthesia with radiological and ultrasound examination of the surgical specimen. The formal histological result confirmed a completely excised rhabdomyoma with clear margins.

In the microbiopsy, the lesion consisted of sheets and trabeculae of large polygonal cells; their cytoplasm was granular and eosinophilic and their nucleus was small and regular. No mitoses were found. The cells surrounded the galactophore and infiltrated the lobules, the interlobular fibrous tissue, and the adipose tissue (Fig. 2). The diagnosis of granular cell tumor was proposed and confirmed by a strong reactivity for S-100 protein, moderate reactivity for neurospecific enolase, and mild expression for calretinin (Fig. 3).

In the biopsy, the lesion measured $1.5 \times 1 \times 1.3 \mathrm{~cm}$ and was relatively well circumscribed. The cut surface was yellow and the lesion had a firm consistency. It was formed by the same cells as those observed in the microbiopsy. Except for a few cystic ducts, the mammary gland had a normal appearance.

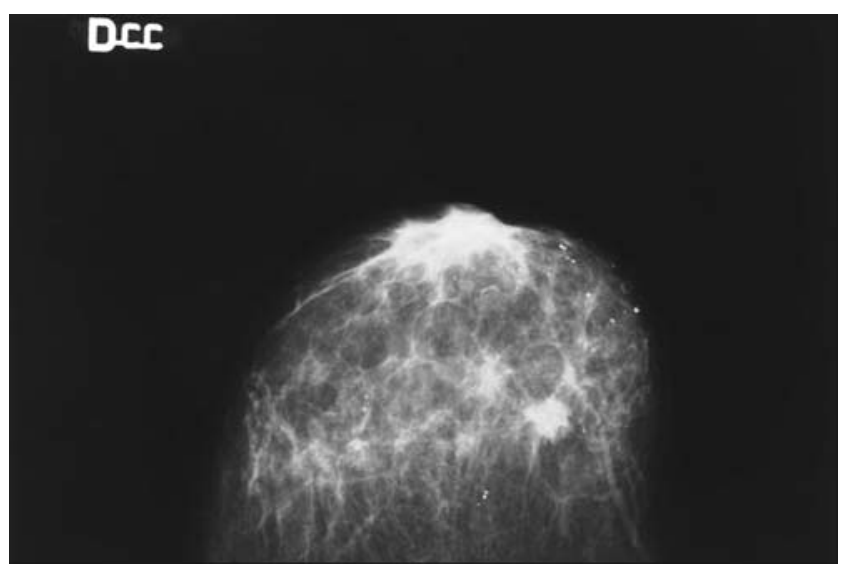

Fig. 1 Mammogram of the right breast - craniocaudal view. Detection of a spiculated opacity $15 \mathrm{~mm}$ in diameter in the superomedial area

\section{Discussion}

Abrikossoff's rhabdomyoma of the breast is a rare benign tumor. It appears between the fourth and the sixth decade in the female and black population [5]. Schwann's theory [6] is the currently favored hypothesis for the histogenesis of this tumor. It may occur as a sequela to an inflammatory breast lesion, or following trauma or breast surgery.

Clinically, the granular cell tumor can present as a round nodule, with well-defined limits and a firm consistency. It is usually quite small and can be adherent to the skin if superficially situated, giving rise to cutaneous retraction and/or nipple inversion [1]. It may also appear as a wellcircumscribed or stellate mass, indurated or firm in consistency, strongly suggestive of a malignant lesion [6]. It may or may not be associated with axillary lymphadenopathy, especially if located in the superomedial quadrant [7]. Its localization follows the supraclavicular nerve [1]. It may also be fixed to the pectoral muscle [7].

Radiological studies can show the rhabdomyoma to be a round opacity or a more suspect image, like a poorly delineated stellate opacity. It may be found on routine breast screening in the absence of all clinical signs. It can appear in the form of a hypoechogenic solid mass, with posterior reinforcement depending on the extent of the infiltration and the degree of reactional fibrosis. The role of RMN and PET scan imaging seems promising in confirming the nature of the tumor pre-operatively [8].

Histologically, Abrikossoff's breast tumor is made from fusiform and granular polygonal cells with abundant cytoplasm. The stroma is divided by bands of uniform round or oval cells [9]. It is a poorly circumscribed tumor 

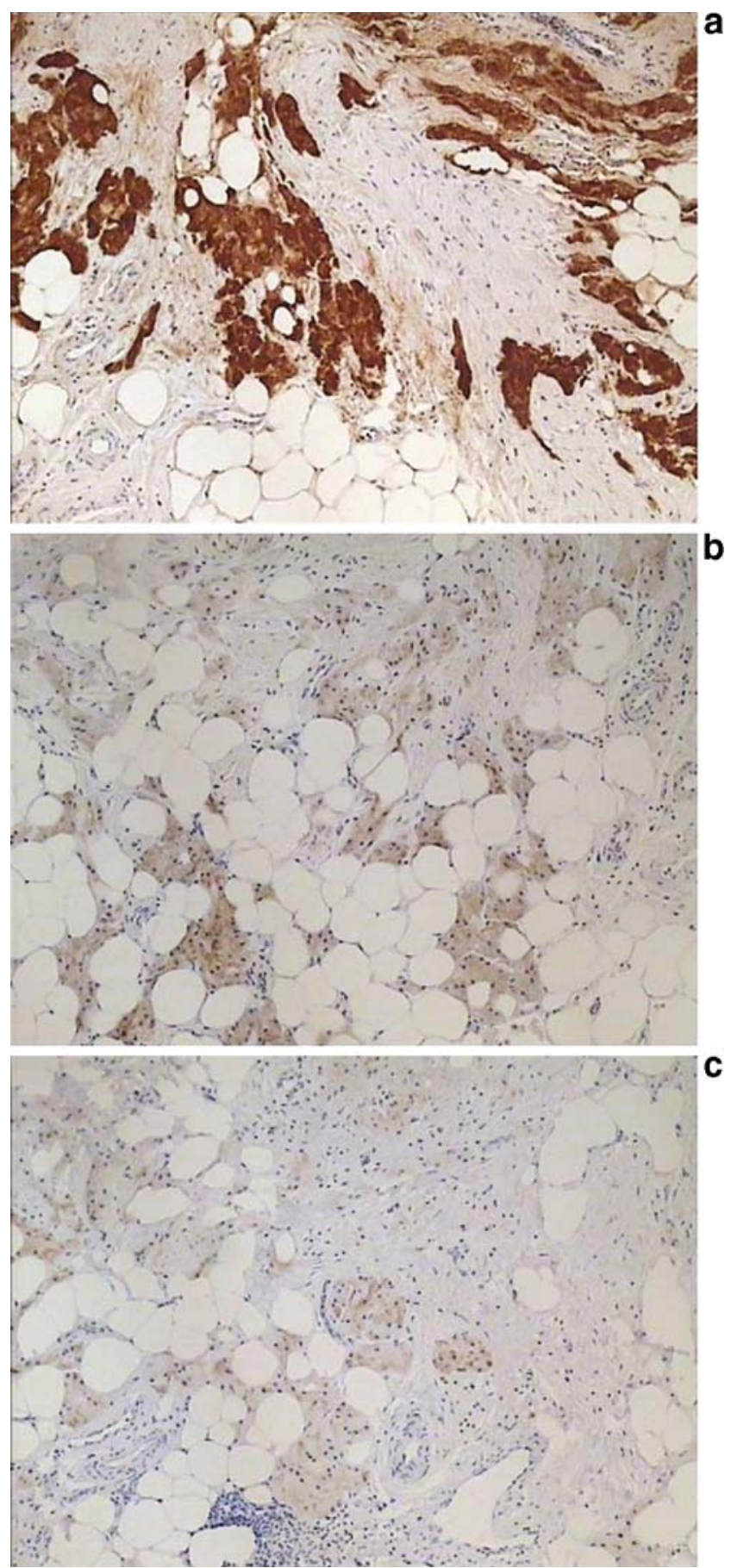

Fig. 3 Confirmation of the granular cell tumor. a Strong reactivity for S-100 protein. b Moderate reactivity for neurospecific enolase. c Mild expression of calretinin of the granular cell tumor

without a capsule and it infiltrates surrounding tissues [4]. Tight connexions may form between the granular cells and peripheral nerve bundles leading to images of perineural invasion that resembles invasive carcinoma. The adjacent epidermis exhibits moderate acanthosis and sometimes genuine pseudoepitheliomatous epithelial hyperplasia [10].

Cytological studies can contribute to the diagnosis if the fine-needle aspiration biopsy of the lesion harvests enough granular cellular elements. The microbiopsy allows the diagnosis to be confirmed before the excision and avoids unnecessary major surgery.

The histological differential diagnosis of a benign or malignant granular cell tumor of the breast may prove to be difficult. The presence of intense mitotic activity, of nuclear pleomorphism, and of signs of necrosis must give rise to suspected malignancy. However this remains very rare$2 \%$ of cases according to Delaloye et al. [1].

The immunohistochemistry affords differentiation between a rhabdomyoma of the breast and a malignant tumor. Immunolabeling shows, in an intense and diffuse way, granular cells positive for S-100 protein, vimentin, and neurospecific enolase [1]. The positivity for calretinin, S-100 protein, and neurospecific enolase excludes a histiocytic origin, which is sometimes suggested by the morphological aspect, and a myoblastic origin, as evoked in the past for this tumor. Its cell immunoreactivity confirms the neural origin [11].

The management of the breast tumor of Abrikossoff is similar to that of a malignant breast tumor. The morphology is very deceptive. It often poses problems of differential diagnosis with invasive carcinoma, clinically, radiologically or histologically. Simple resection is curative in most cases [4]. Lesions are in general well circumscribed. They relapse only in rare cases after resection and do not metastasize. Local recurrence, in particular when there are multiple, rapidly growing tumors, must suggest malignancy of the granular cell tumor. A rare familial multicentric form is also recognized [10].

\section{Conclusion}

Abrikossoff's tumor is a benign lesion, very probably of Schwannian origin. It can affect the skin and several organs, as well as the mammary gland. Rhabdomyomata can simulate malignant lesions both clinically and radiologically. A spiculated opacity must be presumed malignant until proven otherwise. Despite its apparent infiltrating nature, Abrikossoff's tumor is in fact benign, and it is often treated too aggressively as extemporaneous histological examination can be misleading. Cytology is an essential factor in the diagnosis if enough cellular elements are obtained. A good quality preoperative biopsy is highly conclusive in making the diagnosis and simple surgical excision is sufficient. Abrikossoff's tumor is often an unexpected histological diagnosis. 


\section{References}

1. Delaloye JF, Roshong-Denk Seraj F, Guillou L, Genton CY, Anciaux-Le Teno D, Schnyder P, De Grandi P (2002) Granular cell tumor of the breast: a diagnostic pitfall. Breast 1(4):316-319

2. Abrikossoff A (1926) Über Myome, ausgehend von der quergestreiften, willkürlichen Muskulatur. Virchows Arch Pathol Anat 260:215-233

3. Rosso R, Scelsi M, Carnevali L (2000) Granular cell traumatic neuroma: a lesion occurring in mastectomy scars. Arch Pathol Lab Med 124(5):709-711

4. Rossi ED, Mule' A, Miraglia A, Cianfrini F, Zannoni GF, Fadda G (2005) Granular cell tumour on conventional cytology and thinlayer smears. Cytopathology 16(5):259-261

5. Roshong-Denk SL, Montagnese MD, Staren E, Zaher A (2003) Pathologic quiz case: an upper outer quadrant breast mass in a 47- year-old African American woman. Granular cell tumor. Arch Pathol Lab Med 127(11):1525-1526

6. Guray M, Sahin AA (2006) Benign breast diseases: classification, diagnosis, and management. Oncologist 11(5):435-449

7. Porter GJR, Evans AJ, Lee AHS, Hamilton LJ, James JJ (2006) Unusual benign breast lesions. Clin Radiol 61:562-569

8. Hoess C, Freitag K, Kolben M, Allgayer B, Laemmer-Skarke I, Nathrath WB, Avril N, Roemer W, Schwaiger M, Graeff H (1998) FDG PET evaluation of granular cell tumor of the breast. J Nucl Med 39(8):1398-1401

9. Liu K, Madden JF, Olatidoye BA, Dodd LG (1999) Features of benign granular cell tumor on fine needle aspiration. Acta Cytol 43(4):552-557

10. Damiani S, Dina R, Eusebi V (1999) Eosinophilic and granular cell tumors of the breast. Semin Diagn Pathol 16(2):117-125

11. Dabbs D (2006) Diagnostic immunohistochemistry, 2nd edn. Churchill Livingstone, Philadelphia 